\title{
A TEM Investigation of the Stepped Bainite Reaction in Silicon Steels
}

\author{
G. Papadimitriou and G. Fourlaris* \\ National Technical University of Athens, Department of Mining and Metallurgical Engineering, \\ Laboratory of Physical Metallurgy, Zografou 15780, Athens, Greece \\ *School of Materials, The University of Leeds, Leeds LS2 9JT, U.K.
}

\begin{abstract}
The bainitic reaction in steels has been extensively studied, however it is still controversial whether it proceeds by a diffusional or a shear mechanism. In a previous investigation of the bainite reaction in a Fe-3.9Si-0.9C steel the transformation was considered to be the result of two competing elementary mechanisms, i.e., the shear transformation of the $\gamma$-iron lattice and the diffusion of interstitial carbon away from the transformation interface. According to this model, the transition from upper to lower bainite occurs when the rate of interstitial carbon traversing the $\gamma / \alpha$ interface becomes of the same order with the velocity of the shear front. This interpretation stipulates that the carbon content corresponding to the $\gamma / \alpha$ and $T_{o}$ curves of austenite is critical. Using step quench experiments and determining the percentage of the residual austenite and its carbon content it was demonstrated that both $\mathrm{X}_{\gamma / \alpha}$ and $\dot{\mathrm{X}}_{\mathrm{To}}$ contents of austenite play an important role in the initiation of its decomposition and its incomplete transformation. In this paper, the microstructural and crystallographic characteristics of the bainite products obtained through the step quenching experiments are examined, using TEM and Electron diffraction. The results are compared to those obtained by the corresponding bainitic transformation in a single step. The obtained results clearly corroborate the aforementioned model of transformation, which necessitates both a shear mechanism of the iron lattice and a redistribution of carbon between the parent phase and its transformation products.
\end{abstract}

\section{INTRODUCTION}

The bainitic reaction in steels has been extensively studied, however it is still controversial whether it proceeds by a diffusional or a shear mechanism [1-3].

In a previous investigation of the bainite reaction in a $\mathrm{Fe}-3.9 \mathrm{Si}-0.9 \mathrm{C}$ steel the transformation was considered to be the result of two competing elementary mechanisms, i.e., the shear transformation of the $\alpha$ iron lattice and the diffusion of interstitial carbon away from the transformation interface. According to this model, the transition from upper to lower bainite occurs when the rate of interstitial carbon traversing the $\gamma / \alpha$ interface becomes of the same order with the velocity of the shear front. Using step quench experiments and determining the percentage of the residual austenite and its carbon content it was demonstrated that both $\mathrm{X}_{\gamma / \alpha}$ and $\mathrm{X}_{\mathrm{To}}$ contents of austenite play an important role in the initiation of its decomposition and its incomplete transformation [4].

In this paper, the microstructural and crystallographic characteristics of the bainite products obtained through the step quenching experiments are examined, using TEM and Electron diffraction. The results are compared to those obtained by the corresponding bainitic transformation in a single step. The results obtained here support the proposed model in [4] and the shear character of the bainitic transformation [7].

\section{EXPERIMENTAL}

The same steel as in [4], an alloy with 3.9 w.t.\% silicon and 0.9 w.t.\% carbon, was used. After austenitizing at $1130^{\circ} \mathrm{C}$ for 30 minutes a number of samples were transformed at $420^{\circ} \mathrm{C}$ for 30 minutes and then quenched in a second bath where they were kept for times increasing from one to thirty days at temperatures of either 360,340 or $290^{\circ} \mathrm{C}$. The microstructure of the samples was examined using TEM and Electron Diffraction. 


\section{RESULTS AND DISCUSSION}

When the bainite reaction in the Si- alloyed steel under consideration is initiated at $420^{\circ} \mathrm{C}$, it soon reaches a transformation "stasis" after a period of 30 minutes, corresponding to 51 at.\% decomposition of austenite. The microstructure and the kinetics of the primary stage have been discussed elsewhere [5-6]. The product consists of a mixture of bainitic ferrite in the form of needles composed of smaller sub-units and residual austenite, enriched up to a content of 1.83 w.t.\% carbon [4]. No carbides are precipitated, unless the reaction is prolonged for several days. The orientation relationship between ferrite and austenite is very close to that of Nishiyama-Wassermann, i.e. : $(011)_{\mathrm{b}} / /(111)_{\mathrm{f}},[0 \overline{1} 1]_{\mathrm{b}} / /[1 \overline{1} 2]_{\mathrm{f}}$ and $[100]_{\mathrm{b}} / /[1 \overline{1} 0]_{\mathrm{f}}[6]$.

When the partially transformed samples are isothermally treated to a lower reaction temperature of either 360 or $340^{\circ} \mathrm{C}$ no change in the previous microstructure obtained at $420^{\circ} \mathrm{C}$ is observed, apart from a slight increase in the carbon content of the enriched austenite.

However, when the second reaction temperature is set as low as $290^{\circ} \mathrm{C}$, further decomposition of austenite occurs, producing a second generation of bainitic ferrite. The residual austenite is 36 at.\% and is further enriched to 2.03 w.t. \% carbon.

The micrograph of Figure 1 shows that apart from the well known massive ferrite needles of the first generation formed at $420^{\circ} \mathrm{C}$ (marked $\alpha_{1}$ ), a second generation of ferrite (marked $\alpha_{2}$ ) is easily distinguished. This second generation of ferrite, shown better in Fig.2, is much finer. Figures 3 and 4 are the dark field images of the second generation of ferrite and austenite respectively shown in Fig.2. The corresponding selected area diffraction pattern is shown in Figure 5. It is confirmed that the orientation relationship between the austenite and the second generation of ferrite is close to the Kurdjumov-Sachs relationship, i.e.

$$
(011)_{\mathrm{b}} / /(\overline{\mathrm{i}} \overline{1} \overline{1})_{\mathrm{f}},[111]_{\mathrm{b}} / /[10 \overline{\mathrm{l}}]_{\mathrm{f}} \text { and }[2 \overline{1} 1]_{\mathrm{b}} / /[1 \overline{2} 1]_{\mathrm{r}} \text {. }
$$

Figs. 6 and 7 allow a direct comparison of the microstructural characteristics of bainite formed at 420 and $290^{\circ} \mathrm{C}$. The needles formed at $420^{\circ} \mathrm{C}$ have a total width of about 1 to $2 \mu \mathrm{m}$, while the needles formed at $290^{\circ} \mathrm{C}$ have a total width of only 0.05 to $0.3 \mu \mathrm{m}$. However in both of them needles appear as packets of smaller sub-units. The subunits formed at $290^{\circ} \mathrm{C}$ are finer and more elongated and in some cases do not appear to form packets but they are rather isolated.

The austenite surrounding the ferrite needles formed at $420^{\circ} \mathrm{C}$ has a high density of dislocations, which is higher near the austenite /ferrite interface (Fig.6). The austenite entrapped between the needles of the second generation ferrite formed at $290^{\circ} \mathrm{C}$ contains, apart from clusters of dislocations associated to the $\gamma / \alpha$ interface, extensive faulting. Fig. 8 is the bright field image of austenite in contact with a second generation ferrite needle. The corresponding diffraction pattern of Fig.9 shows that the defects are twins with a $(111)_{\mathrm{f}}$ twinning plane. Figure 10 is a dark image field taken on a (020)-twin reflection of austenite."

The fact that the austenite twins occur systematically in contact with the second generation of ferrite, while they are only exceptionally present near the first generation of ferrite or in samples reacted only at $420^{\circ} \mathrm{C}$, shows that they are associated to the formation of the second generation of ferrite. This implies that the austenite is highly stressed during the transformation at $290^{\circ} \mathrm{C}$. The formation of twins should be connected to the shape strain accompanying the formation of ferrite, i.e. the shear character of the transformation, combined to the difficulty of stress relaxation at this low temperature. Another important factor may be the lower diffusivity of carbon causing the ferrite to stay for a longer time in supersaturation. This is in agreement with the hypothesis done in [4] that at temperatures below $300-310^{\circ} \mathrm{C}$ the diffusion of carbon away of the forming ferrite subunit is slower than the rate of shear of the iron lattice.

These results corroborate clearly the aforementioned model of the bainitic transformation [4], which necessitates both a shear mechanism of the iron lattice and a redistribution of carbon between the parent phase and its transformation products. Furthermore it is interesting to note that no second generation of ferrite was observed when the second isothermal treatment was done at 360 (or at $340^{\circ} \mathrm{C}$ ), although at these temperatures a slight enrichment of austenite beyond its original value of 1.83 w.t.\% carbon was observed. This is in agreement with the hypothesis that at the end of the primary stage at $420^{\circ} \mathrm{C}$ the carbon content of austenite (1.83 w.t.\% carbon) is between the $\mathrm{x}_{\mathrm{T}}$ and $\mathrm{x}_{\mathrm{\gamma} / \alpha}$ at the temperatures of the second isothermal treatment, and consequently the transformation by shear is impossible, although some diffusional growth of the ferrite needles leading to a slight enrichment of austenite is possible. In contrast, a second generation of bainitic ferrite forms at $290^{\circ} \mathrm{C}$, where apparently, the original carbon content of austenite $(1.83$ w.t.\% carbon) is lower than the $\mathrm{x}_{\mathrm{T}}$ value at $290^{\circ} \mathrm{C}$. Indeed, the ferrite formed at $290^{\circ} \mathrm{C}$ is really a bainite and has its main microstructural characteristics in common with the bainite formed at $420^{\circ} \mathrm{C}$. 
These observations show that the carbon content of austenite, compared to the $\mathrm{x}_{\mathrm{To}}$ and $\mathrm{x}_{\mathrm{\gamma} / \alpha}$ values at the temperature of the transformation are crucial for the bainitic transformation, as it is explained in [4].

\section{References}

[1] Aaronson H.I., Reynolds W.T., Shiflet G.J. Jr and Spanos G., Metall Trans, A, Vol. 21A (1990), 13431380.

[2] Bhadeshia H.K.D.H. and Edmonds D.V., Acta Met., Vol.28 (1980),1265-1273.

[3] Sandvik B.P.J. Met.Trans. A, Vol. 13A, (1982),777-787.

[4] Papadimitriou G and Genin J.M., "Fundamental mechanisms of the bainitic transformation based on the case of an $\mathrm{Fe}-0.9-3.85 \% \mathrm{Si}$ alloy", Proceedings of the International Conference on Martensitic Transformations, Nara Japan, (1986) The Japan Institute of Metals,pp607-612.

[5] Papadimitriou G, Courrier R and Genin J.M. "Etude cinétique de la première étape de décomposition de $1^{\prime}$ ' austénite d'une bainite Fe-C-Si", C.R.Acad.Sc.Paris,Vol. 276C (1973), p.739.

[6] Papadimitriou G. and Genin J.M., "Kinetic and thermodynamic aspects of the bainite transformation in a high carbon silicon containing steel", "Phase Transformations in Solids", Symposium Proceedings, Vol.21 (1984) Ed. Th Tsakalakos, Materials Research Society, pp.747-755.

[7] Fourlaris G., Baker. A.J. and Papadimitriou G., Acta Mat., Vol.44, 12 (1996), 4791-4805.

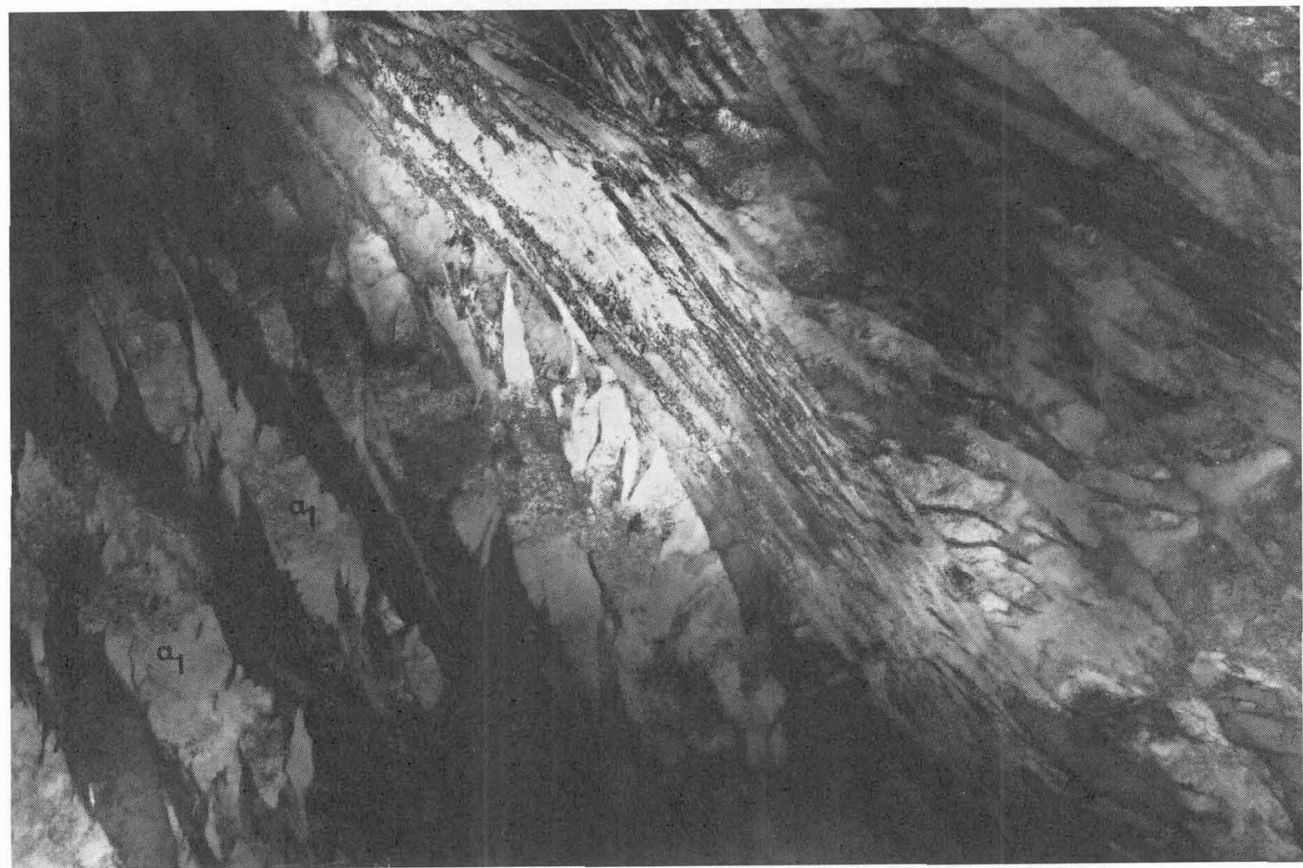

$30 \mathrm{~nm}$

Figure 1: Bright field transmission electron micrograph of bainite obtained after isothermal treatment at $420^{\circ} \mathrm{C}$ for 30 min. and then at $290^{\circ} \mathrm{C}$ for 21 days. Two generations of bainitic ferrite and residual austenite are observed. 


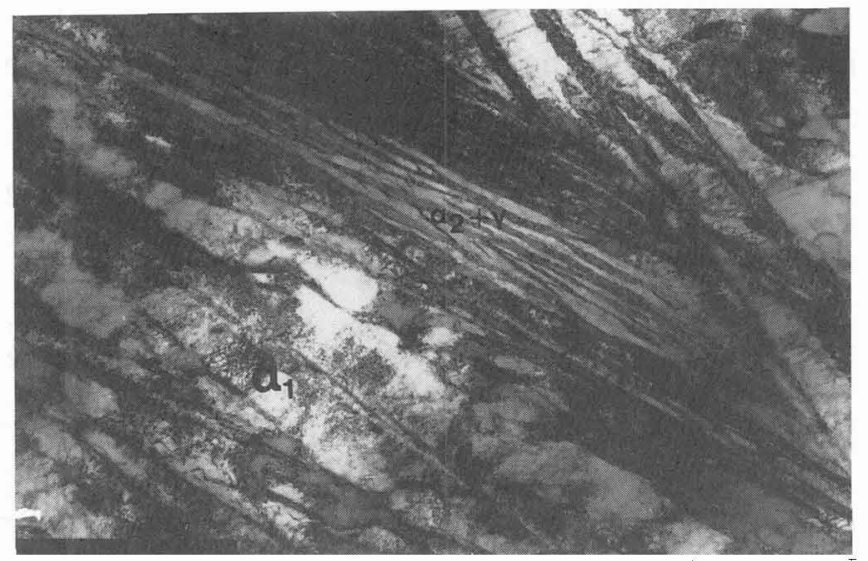

\section{$80 \mathrm{~nm}$}

Figure 2: Bright field transmission electron micrograph of bainite obtained after isothermal treatment at $420^{\circ} \mathrm{C}$ for $30 \mathrm{~min}$. and then at $290^{\circ} \mathrm{C}$ for 21 days. Second generation of bainitic ferrite formed at $290^{\circ} \mathrm{C}$ (fine needles) embedded in austenite.

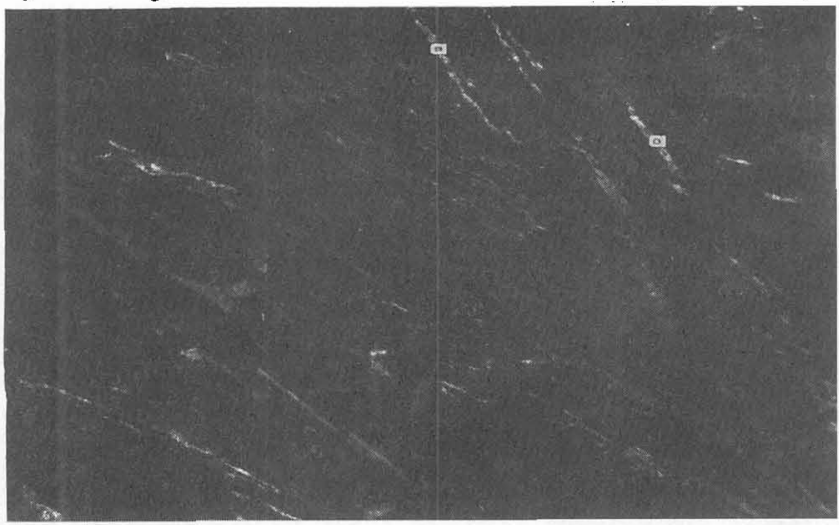

\section{$80 \mathrm{~nm}$}

Figure 3: Dark field TEM micrograph, produced on a (110) reflection of ferrite of Fig.2

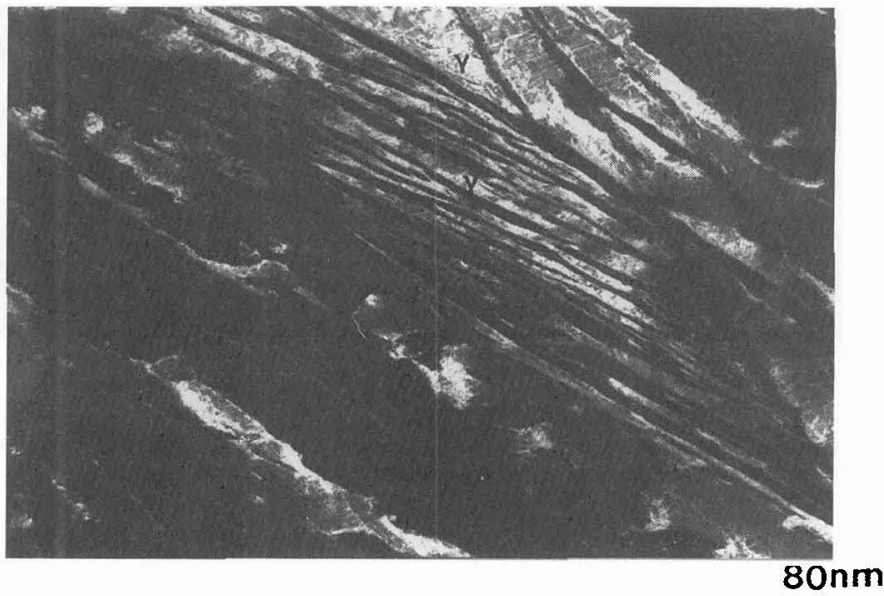

Figure 4: Dark field TEM micrograph, produced on a (202) reflexion of residual austenite of Fig.2. 

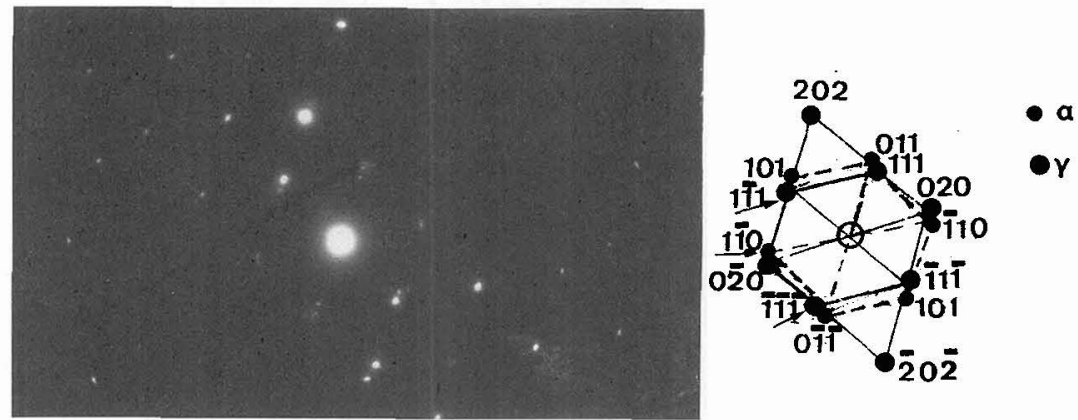

Figure 5: Selected Area Electron diffraction pattern corresponding to Fig. 2 and its indexing. The orientation relationship between ferrite and austenite is close to the Kurdjumov-Sachs relationship.

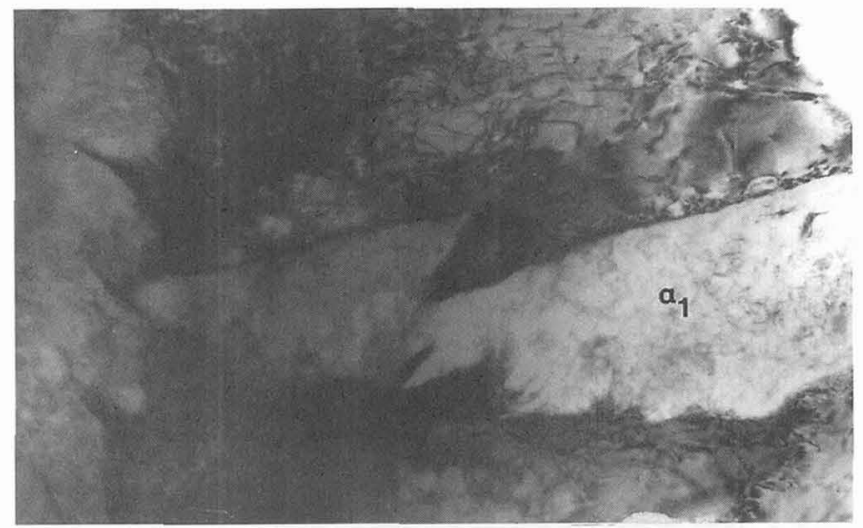

Figure 6: Bright field transmission electron micrograph of bainite obtained after isothermal treatment at $420^{\circ} \mathrm{C}$ for $30 \mathrm{~min}$. and then at $290^{\circ} \mathrm{C}$ for 10 days. First generation of bainitic ferrite formed at $420^{\circ} \mathrm{C}$ (large needles) are observed embedded in austenite. High density of dislocations associated with the ferrite/austenite interface.

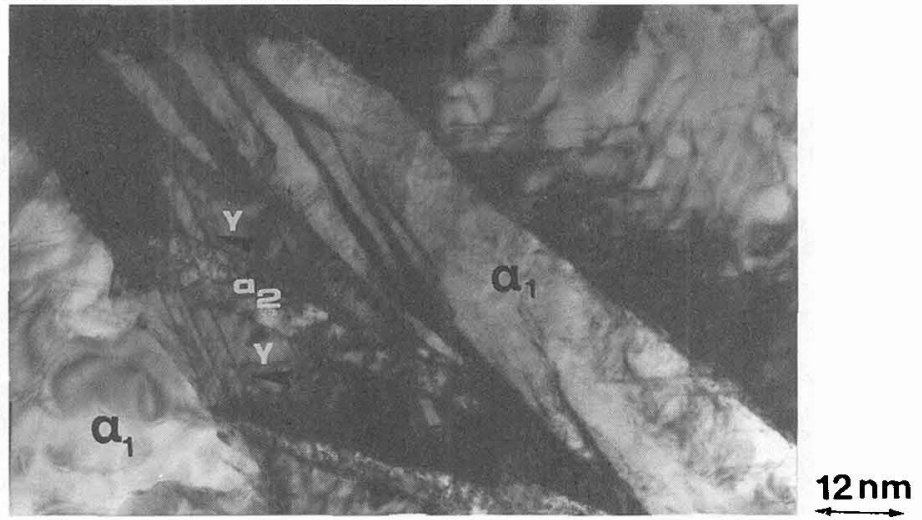

Figure 7: Bright field transmission electron micrograph of bainite obtained after isothermal treatment at $420^{\circ} \mathrm{C}$ for 30 min. and then at $290^{\circ} \mathrm{C}$ for 10 days. Second generation of bainitic ferrite formed at $290^{\circ} \mathrm{C}$ in packets or in isolated needles. The austenite entrapped among them exhibits significant twinning 


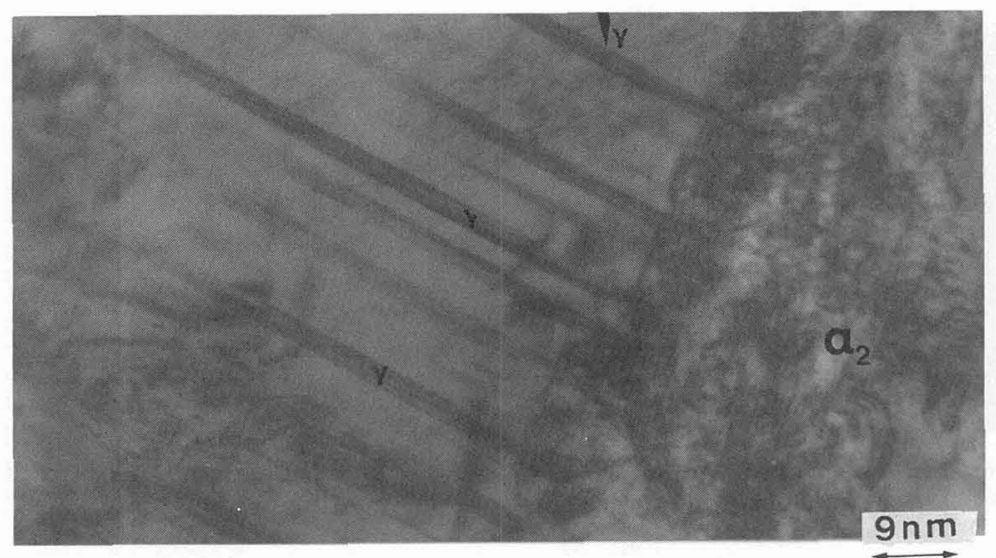

Figure 8: Bright field TEM micrograph of austenite containing twins in contact with a second generation ferrite needle.

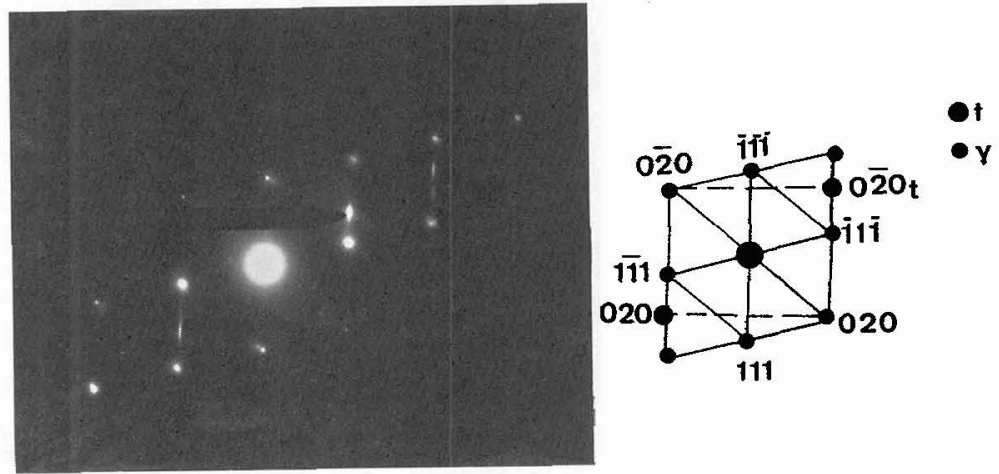

Figure 9:Selected Area Electron Diffraction pattern of austenite with twins.

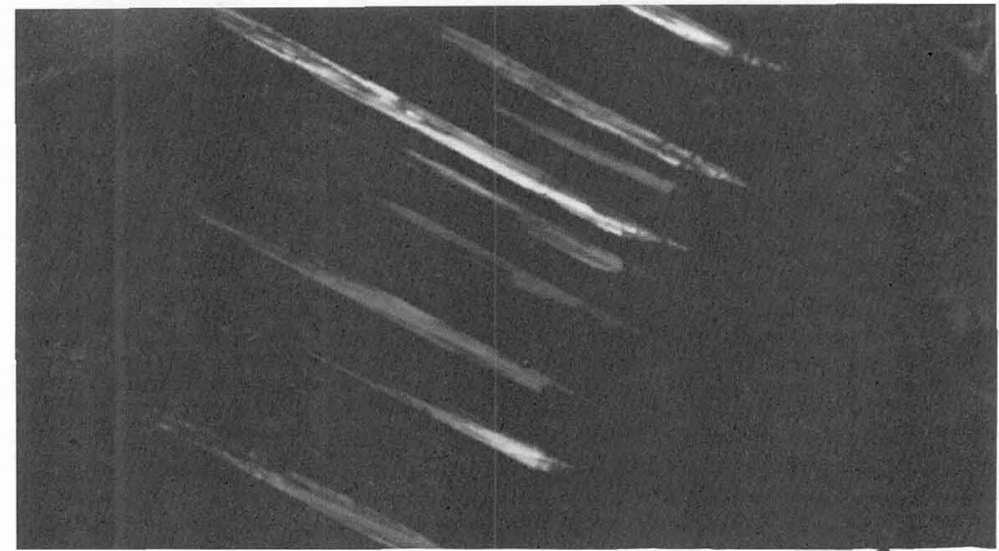

Figure 10: Dark field TEM micrograph of austenite on a 020 twin reflection. 